\title{
Pharmacogenetics of osteoporosis
}

\section{Francesca Marini and Maria Luisa Brandi*}

\author{
Address: Metabolic Bone Unit, Department of Internal Medicine, University of Florence, Viale Pieraccini 6, 50139 Florence, Italy \\ *Corresponding author: Maria Luisa Brandi (m.brandi@dmi.unifi.it) \\ FI000 Biology Reports 2010, 2:63 (doi:10.34I0/B2-63)
}

This is an open-access article distributed under the terms of the Creative Commons Attribution-NonCommercial License (http://creativecommons.org/licenses/by-nc/3.0/legalcode), which permits unrestricted use, distribution, and reproduction in any medium, for non-commercial purposes provided the original work is properly cited. You may not use this work for commercial purposes.

The electronic version of this article is the complete one and can be found at: http://f1000.com/reports/biology/content/2/63

\begin{abstract}
Osteoporosis is a complex bone disorder with a strong genetic basis. The genetics of osteoporosis encompasses two main areas: genetics of disease susceptibility and pharmacogenetics of drug response. The former has been widely studied in the past few decades, while the latter is still largely untouched. This review will provide an overview of the pharmacogenetics of osteoporosis, focusing on the major recent advances in the past two years.
\end{abstract}

\section{Introduction and context}

Osteoporosis is the most common and serious skeletal disorder of the elderly, characterized by a reduced density and quality of bone leading to weakness of the skeleton and increased risk of bone fragility and spontaneous fractures, which are associated with up to a three-fold increase in mortality in both sexes [1]. Osteoporosis affects all ethnic groups, with a lifetime risk of hip, forearm, or vertebral fractures being over 40\% [2]. Today osteoporosis represents a global public health problem, affecting over 200 million people worldwide, with important implications for healthcare costs, morbidity, and mortality. Osteoporosis is a complex multifactorial disease, but it is now understood that genetic factors play a central role in its pathogenesis [3].

The genetics of osteoporosis comprises two main areas: genetics of disease susceptibility and pharmacogenetics of drug response. The genetics of osteoporosis predisposition has been widely studied and the results of numerous association studies between polymorphisms of more than 40 candidate genes and bone quantitative and qualitative traits have been published in the literature, although the results of these studies are controversial and no convincing conclusions have emerged yet. Conversely, the study of the pharmacogenetics of osteoporosis is still largely untouched and only a few studies have been published in the past decade. Pharmacogenetics represents the utilization of individual genetic data to predict the outcome of a drug treatment with respect to both beneficial and adverse effects [4-6]. The response of osteoporosis to pharmacotherapy is known to be highly variable between patients. Thus, the emerging field of pharmacogenetics could be very useful for refining and optimizing osteoporosis drug treatment, potentially allowing the identification of the most effective drug and dose for each patient, in terms of beneficial and adverse effects, based on the single genotype. The study of the pharmacogenetics of osteoporosis should include the understanding of molecular mechanisms of drug action, the identification of drug response candidate genes and their variants, and the expansion of clinical trials to include patients' genetic profiling. All these approaches could provide useful tools to tailor decisions about osteoporosis drug treatments in order to maximize the health and well-being of osteoporotic patients.

\section{Major recent advances}

Very few data [7-23] are available to date on the pharmacogenetics of osteoporosis. Some major osteoporosis candidate genes, such as those encoding the vitamin $\mathrm{D}$ receptor $(V D R)$, estrogen receptors alpha $(E R \alpha)$ and beta $(E R \beta)$, and collagen I alpha 1 (COL1A1), have been investigated with regard to anti-resorptive drug (i.e., hormone replacement therapy, raloxifene, and bisphosphonates) responses. Most of these studies associated variation in drug response, evaluated in 
terms of bone mineral density (BMD) and bone turnover marker variation, with genetic polymorphisms. Nevertheless, the great majority of these studies have investigated only genes that affect BMD and fracture risk and these might be independent from genes that affect drug responses. The variability in drug response is much more complicated than simple variability in $\mathrm{BMD}$ or bone turnover markers; thus, it will be very important to define the phenotypes of antiresorptive drug response and to enlarge pharmacogenetic studies to also include genes involved in drug-specific pharmacokinetics and pharmacodynamics.

Four novel studies have been published in the past two years in the field of genetics of osteoporosis. In 2008, Simsek et al. [7] evaluated the effects of the Sp1 polymorphism in intron 1 of the COL1A1 gene on $\mathrm{BMD}$ response to at least 3 years of low-dose hormone replacement therapy in 111 postmenopausal Turkish women. The increase in spinal and femoral BMD was higher in women with the SS genotype compared to those with the Ss genotype.

In the same year, our research group [8] associated the A/ C rs2297480 polymorphism in intron 1 of the farnesyl pyrophosphate synthase gene (FDPS), the molecular target of amino-bisphosphonates in osteoclasts, with the response to 2-year aminobisphosphonate treatment in 234 osteoporotic Danish women. We found that subjects with the homozygous CC genotype showed a decreased response by urinary Crosslaps after 2 years, but not after 1 year, of amino-bisphosphonate therapy when compared to the heterozygous $\mathrm{AC}$ and to the homozygous AA genotypes.

In 2009, Kruk et al. [9] failed to find any association between the V667M polymorphism (exon 9) and the A1330V polymorphism (exon 18) of the low-density lipoprotein receptor-related protein 5 gene (LRP5) and $\mathrm{BMD}$ and bone turnover response to 2-year risedronate treatment in a cohort of 249 osteoporotic or osteopenic men.

Very recently, Choi et al. [10] analyzed the role of the rs2297480 (intron 1) and rs11264361 (intron 8) polymorphisms of the FDPS gene and the rs3840452 (promoter region) and $r s 3841735$ (intron 3) polymorphisms of the geranylgeranyl diphosphate synthase 1 gene (GGPS1) and the response, in terms of changes in lumbar spine and femoral neck BMD, to 1-year bisphosphonate treatment in 144 osteoporotic Korean women. Women with two deletion alleles $(-8188 \mathrm{~A} \mathrm{del})$ of the rs3840452 polymorphism of the GGPS1 gene presented a significantly lower improvement in BMD than women with only one deletion allele or no deletion alleles. Women with two deletion alleles had a seven-fold higher risk of non-response to bisphosphonates compared with women with the other two genotypes, after adjusting for baseline BMD.

Results from these studies seem to suggest that patient genotyping could be useful to target osteoporosis drug treatments to subjects most likely to respond in terms of $\mathrm{BMD}$ and bone turnover marker variation. However, association studies can have some limitations, such as inadequate sample size or sampling errors, genetic differences between different ethnic groups, the presence of gene-gene and/or gene-environment interactions acting as confounding factors, the complexity of genome and gene regulation (epigenetic factors, somatic mutations, microRNAs, and so on), and frequent accidental statistical association not due to a real association between genotype and phenotype. For all these reasons, at the moment no definite gene variations have been conclusively shown to be responsible for the regulation of any anti-osteoporosis drug response.

\section{Future directions}

Patient genotyping could be useful for targeting osteoporosis drug treatments to subjects most likely to respond well, avoiding suboptimal long-term treatments or adverse reactions. The application of specific genetic tests to identify subjects most likely to respond well and not to develop adverse reactions before the beginning of drug treatment is important mostly for those diseases, such as osteoporosis, for which numerous and effective therapies are available and, therefore, for which the selection of the optimal therapy is foreseeable. Moreover, the pharmacogenetics could help to map novel molecular drug targets, with an impact on drug discovery, moving from 'one drug fits all' to personalized therapy. Certainly, the genes to be evaluated should always encompass those encoding drug targets, drug metabolizing enzymes, and drug transporters, and pharmacogenetics will need to apply novel strategies in the search for gene variation, such as genome-wide scan association studies, microarray analysis, and the application of Bayesian methodology. Moreover, pharmacogenetic association studies need to be extended and confirmed in large cohorts, in different ethnic groups and/or in multicentric studies, and all gene variants positively correlated with drug response in association studies will have to be validated by functional in vitro, in vivo, and ex vivo studies.

\section{Abbreviations}

$\mathrm{BMD}$, bone mineral density; COL1A1, collagen I alpha 1; FDPS, farnesyl pyrophosphate synthase; GGPS1, geranylgeranyl diphosphate synthase 1 . 


\section{Competing interests}

The authors declare that they have no competing interests.

\section{Acknowledgments}

This works was supported by FIRMO, Fondazione Raffaella Becagli.

\section{References}

I. Kanis JA: Diagnosis of osteoporosis and assessment of fracture risk. Lancet 2002, 359:1929-36.

2. Nguyen TV, Eisman JA: Pharmacogenomics of osteoporosis: opportunities and challenges. J Musculoskelet Neuronal Interact 2006, 6:62-72.

3. Styrkarsdottir U, Halldorsson BV, Gretarsdottir S, Gudbjartsson DF, Walters GB, Ingvarsson T, Jonsdottir T, Saemundsdottir J, Center JR, Nguyen TV, Bagger Y, Gulcher JR, Eisman JA, Christiansen C, Sigurdsson G, Kong A, Thorsteinsdottir U, Stefansson K: Multiple genetic loci for bone mineral density and fractures. $N$ Engl J Med 2008, 358:2355-65.

FI000 Factor 8.0 Exceptional

Evaluated by Peter Ebeling 16 Jun 2008, Robert Plenge 24 Jun 2008

4. Jhonson JA, Evans WE: Molecular diagnostics as a predictive tool: genetics of drug efficacy and toxicity. Trends Mol Med 2002, 8:300-5.

5. Weber WW: Effect of pharmacogenetics on medicine. Environ Mol Mutagen 200I, 37:179-184.

6. Manolopoulos VG: Pharmacogenomics and adverse drug reactions in diagnostic and clinical practice. Clin Chem Lab Med 2007, 45:80I-I4.

7. Simsek M, Cetin Z, Bilgen T, Taskin O, Luleci G, Keser I: Effects of hormone replacement therapy on bone mineral density in Turkish patients with or without COLIAI Spl binding site polymorphism. J Obstet Gynaecol Res 2008, 34:73-7.

8. Marini F, Falchetti A, Silvestri S, Bagger Y, Luzi E, Tanini A, Christiansen C, Brandi ML: Modulatory effect of farnesyl pyrophosphate synthase (FDPS) rs2297480 polymorphism on the response to long-term amino-bisphosphonate treatment in postmenopausal osteoporosis. Curr Med Res Opin 2008, 24:2609-I5.

9. Kruk M, Ralston SH, Albagha OM: LRP5 polymorphisms and response to risedronate treatment in osteoporotic men. Calcif Tissue Int 2009, 84:171-9.

10. Choi HJ, Choi JY, Cho SW, Kang D, Han KO, Kim SA, Kim SY, Chung YS, Shin CS: Genetic polymorphism of geranylgeranyl diphosphate synthase (GGSPI) predicts bone density response to bisphosphonate therapy in Korean women. Yonsei Med J 2010, 5 I:231-8.

I I. Yahata T, Quan J, Tamura N, Nagata H, Kurabayashi T, Tanaka K: Association between single nucleotide polymorphisms of estrogen receptor alpha gene and efficacy of HRT on bone mineral density in post-menopausal Japanese women. Hum Reprod 2005, 20:1860-6.
12. Rapuri PB, Gallagher JC, Knezetic JA, Haynatzka V: Estrogen receptor alpha gene polymorphisms are associated with changes in bone remodeling markers and treatment response to estrogen. Maturitas 2006, 53:37I-9.

13. Ongphiphadhanakul B, Chanprasertyothin S, Payatikul P, Tung SS, Piaseu N, Chailurkit L, Chansirikarn S, Puavilai G, Rajatanavin R: Oestrogen-receptor-alpha gene polymorphism affects response in bone mineral density to oestrogen in postmenopausal women. Clin Endocrinol (Oxf) 2000, 52:58I-5.

14. Salmén T, Heikkinen AM, Mahonen A, Kröger $H$, Komulainen $M$, Saarikoski S, Honkanen R, Mäenpää $\mathrm{PH}$ : The protective effect of hormone-replacement therapy on fracture risk is modulated by estrogen receptor alpha genotype in early postmenopausal women. J Bone Miner Res 2000, I5:2479-86.

15. Kurabayashi T, Tomita M, Matsushita H, Yahata T, Honda A, Takakuwa K, Tanaka K: Association of vitamin $\mathbf{D}$ and estrogen receptor gene polymorphism with the effect of hormone replacement therapy on bone mineral density in Japanese women. Am J Obstet Gynecol 1999, I80: I I I5-20.

16. Kurabayashi T, Matsushita H, Tomita M, Kato N, Kikuchi M, Nagata H, Honda A, Yahata T, Tanaka K: Association of vitamin $\mathbf{D}$ and estrogen receptor gene polymorphism with the effects of longterm hormone replacement therapy on bone mineral density. J Bone Miner Metab 2004, 22:24I-7.

17. Giguère $Y$, Dodin S, Blanchet $C$, Morgan K, Rousseau F: The association between heel ultrasound and hormone replacement therapy is modulated by a two-locus vitamin $D$ and estrogen receptor genotype. J Bone Miner Res 2000, I 5: I 076-84.

18. Palomba S, Numis FG, Mossetti G, Rendina D, Vuotto P, Russo T, Zullo F, Nappi C, Nunziata V: Raloxifene administration in postmenopausal women with osteoporosis: effect of different Bsml vitamin D receptor genotypes. Hum Reprod 2003, I 8: I 92-8.

19. Heilberg IP, Hernandez E, Alonzo E, Valera R, Ferreira LG, Gomes SA, Bellorin-Font E, Weisinger JR: Estrogen receptor (ER) gene polymorphism may predict the bone mineral density response to raloxifene in postmenopausal women on chronic hemodialysis. Ren Fail 2005, 27:I55-6I.

20. Marc J, Prezelj J, Komel R, Kocijancic A: VDR genotype and response to etidronate therapy in late postmenopausal women. Osteoporos Int 1999, 10:303-6.

21. Palomba S, Orio F Jr, Russo T, Falbo A, Tolino A, Manguso F, Nunziata V, Mastrantonio P, Lombardi G, Zullo F: Bsml vitamin D receptor genotypes influence the efficacy of antiresorptive treatments in postmenopausal osteoporotic women. A I-year multicenter, randomized and controlled trial. Osteoporos Int 2005, 16:943-52.

22. Arko B, Prezelj J, Komel R, Kocijancic A, Marc J: No major effect of estrogen receptor beta gene Rsal polymorphism on bone mineral density and response to alendronate therapy in postmenopausal osteoporosis. J Steroid Biochem Mol Biol 2002, 81 :|47-52.

23. Qureshi AM, Herd RJ, Blake GM, Fogelman I, Ralston SH: COLIAI Spl polymorphism predicts response of femoral neck bone density to cyclical etidronate therapy. Calcif Tissue Int 2002, 70:158-63. 